\title{
High Speed Synchronous Reluctance Machines: Modeling, Design and Limits
}

\author{
Gianvito Gallicchio, Mauro Di Nardo, Member, IEEE, Marco Palmieri, Member, IEEE, Alessandro Marfoli, \\ Michele Degano, Member, IEEE, Chris Gerada, Senior Member, IEEE, Francesco Cupertino, Senior Member, IEEE
}

\begin{abstract}
An important barrier to the adoption and acceptance of synchronous reluctance (SyR) machines in different applications lies in their non-standardized design procedure. The conflicting requirements incurring at high speeds among electromagnetic torque and structural and thermal limitations can significantly influence the machine performance, leading to a real design challenge. Analytical models used for design purpose lack in accuracy and force the designer to heavily rely on finite element analysis (FEA), at least during the design refinement stage. This becomes even more computationally expensive as the speed increases, as the evaluation of the rotor structural behaviour is required. This work presents a computationally efficient hybrid analytical-FE design process able to consider all the main limiting design aspects of SyR machine incurring at high speed, namely structural and thermal. As a vessel to investigate the proposed design routine accuracy, several high speed SyR machines have been designed for a wide range of operational speeds (up to 70krpm). The thermal and mechanical factors limiting the high speed operation are deeply analyzed aiming at maximize the mechanical output power. The proposed design approach is then validated by comparison against experimental measurements on a $5 \mathrm{~kW}-50 \mathrm{krpm}$ SyR prototype.
\end{abstract}

Index Terms-Analytical design, finite element analysis, high speed, iron bridges, iron losses, structural rotor design, synchronous reluctance machines.

\section{INTRODUCTION}

$\mathbf{I}$ $\mathrm{N}$ the last few decades, Synchronous Reluctance (SyR) machines have attracted increasing attention in several sectors, especially automotive and industry. In the latter, i.e. mainly for low-medium speed applications, SyR machines allow a considerable volume reduction and/or an improvement of the operational efficiency compared to induction motors (IM) [1], [2]. Along with higher efficiency (when compared to IMs), simple rotor construction and absence of permanent magnets are further advantages which make SyR machines a valuable alternative also in the automotive sector. Despite these advantages, high torque ripple and low power factor are the most important drawbacks of this machine topology. A lot of research effort has been dedicated to overcome these issues mainly focusing on the rotor design [3]-[6], which represent the greatest challenge as it involves many degrees of freedom and complex phenomena [7], [8]. Important contributions to the analytical modelling of SyR machines are reported in [9][12]. The fast resolution of the analytical models comes at

G. Gallicchio, M. Palmieri and F. Cupertino are with the Department of Electrical Engineering and Information Technology, Politecnico di Bari, Bari, 70126 Italy e-mail: gianvito.gallicchio@poliba.it.

M. Di Nardo, A. Marfoli, M. Degano and C. Gerada are with the Power Electronics and Machine Control Group, University of Nottingham, Nottingham, NG7 2RD, UK. the cost of the accuracy of the performance prediction. The main assumptions of these models are a simplification of the rotor geometry and linearity of the iron materials. The latter, in some cases, could lead to imprecise prediction mainly due to the complex relation between flux and current [13]. The cross-coupling effects are particularly relevant in SyR machine therefore they must be considered for an accurate prediction of the torque required in the design stage and/or control purpose [14]. An interesting attempt to fully include the saturation effect within an analytical model has been reported in [15] and used in [16] to characterize the machine behaviour also in case of rotor eccentricity. Although interesting, this approach does not allow to define a set of design oriented equations aimed at identifying the performance trade-offs via a reduced number of design variables as in [17]. The latter, along with [18], proposes a comprehensive design procedure (including both stator and rotor) that, under certain assumptions (including the linearity of soft magnetic materials), allows to identify the trade-offs involved in the design of a low speed SyR machine. This set of analytical design equations has been extended in [19] in order to eliminate the hypothesis of linearity of the magnetic materials and so improve the accuracy of the predicted performance. The proposed method uses few finite element simulations carried out on an extremely restricted subset of design solutions, in order to take into account the inevitable non-linearities affecting the SyR machine performance. In general, the design procedure of SyR machine is usually divided in two steps: first an analytical (or hybrid) model is used to carry out a preliminary design; then a Finite Element Analysis (FEA) is employed to fine-tune the design accounting for the aspects disregarded in the first stage. For low speed application, this second design refinement stage is mainly electromagnetic. As the speed increases, this second phase also includes several mechanical FEAs aimed at designing the so-called iron bridges (or ribs, shown in Fig. 1b) to guarantee that the rotor maximum Von Mises stress is below the material yield limit [20]. Indeed, if these structural strengthening iron bridges are widened in order to ensure the rotor integrity at high speed, then the electromagnetic performances quickly deteriorate. As the speed increases, the conflicting requirements between electromagnetic and structural performance pose severe design challenges especially when considering high speed applications. In order to optimize the electromagnetic performance whiles guaranteeing the rotor integrity, several multi-physics design approaches have been proposed. In [21], [22], it has been shown that, if a FE-based optimization is adopted, then dividing the design procedure 
in two steps, i.e., the electromagnetic design followed by a mechanical design, is beneficial for both computational effort and performance of the final solution [23], [24]. In [25], an analytical model has been extended to include the effect of the radial iron ribs on the electromagnetic performance with the aim of assessing analytically the maximum power capability of SyR machines as function of the speed. All these studies, whether based on computational expensive FE automatic design approach, or based on simplified analytical models, have been carried out considering a given stator design. In other words, all these works mainly focus on the rotor design, effectively designing the stator disregarding the effect on the rotor structural behaviour (e.g. choice of the split ratio). By doing so, also the balance between magnetic and electric loads is a-priori selected during the stator design without evaluating its effect on the overall performance.

As the speed increases, also the iron losses become a further limiting factor to consider during the design of a high speed SyR machine. This is a common challenge when designing high speed machines. Indeed, as the maximum speed increases, a different cooling system has to be designed to dissipate the higher iron losses. However, if the total losses are kept constant during the comparative design exercise, by decreasing the Joule losses quota as the iron losses rise, then the cooling system can be maintained unchanged leading to a comparison on a fair basis.

This paper further extends the work presented in [19], [25] [27]. The high speed limiting design factors, namely structural and iron losses, are included within a set of design equations, in order to assess their impact on the overall performance and the geometry of the optimal design solutions. After introducing the extended set of design equations in section II, its limits are reported in section III along with a methodology to improve its accuracy in section IV. The influence of both high speed limiting design aspects are then deeply investigated in sections $\mathrm{V}$ and VI. The drawn general design guidelines are then experimentally validated in section VII.

\section{Analytical Design Equations}

Torque and power factor can be expressed as functions of two independent variables: split ratio $(s r)$, defined as the ratio between the outer rotor radius $\left(R_{r}\right)$ and the outer stator radius $\left(R_{s}\right)$, and the magnetic ratio $(m r)$, which is the ratio between the airgap flux density $\left(B_{g}\right)$ and the iron flux density $\left(B_{f e}\right)$. The remaining geometrical parameters, all depicted in Fig. 1b, can be expressed in terms of these two quantities via physical and geometrical considerations [19]. Both torque and power factor are considered because, in general, the combination of $s r-m r$ which optimizes the torque does not necessarily coincide with the one maximizing the power factor. In fact, the power factor depends only on the inductances, while the torque depends on both inductances and capability of the machine to produce the stator magneto-motive force (m.m.f) and flux, which in turn depends on the geometry and on the constraints imposed during the design (e.g. external radius, electrical loading, current density, total losses, etc.). The hypotheses underlying this set of design equations are:

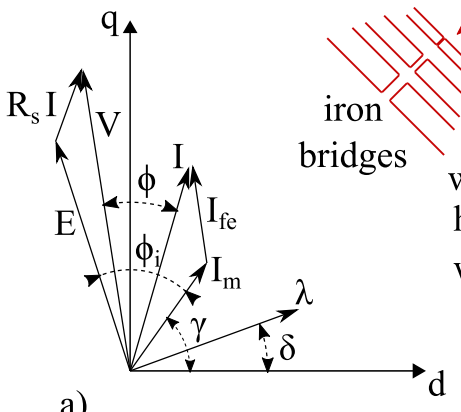

a)

b)

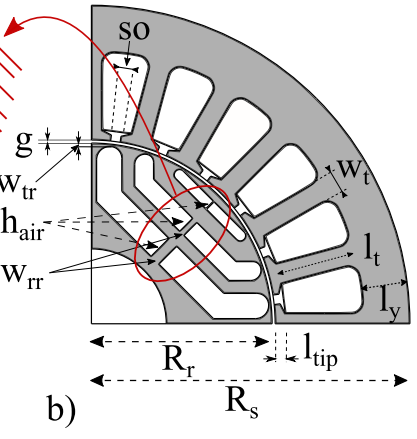

Fig. 1. a) Vector diagram of a SyR machine. b) Parametrization of the stator and rotor geometry.

- the stator outer radius $\left(R_{s}\right)$ and axial length $(L)$ are fixed;

- the iron permeability is assumed to be infinite;

- the power dissipation capability of the cooling system is fixed, which means that the ratio between machine total losses and external surface available for the heat exchange $\left(k_{\text {cool }}\right)$ is given;

- the flux density $B_{f e}$ within each stator and rotor part is preliminary chosen.

The torque produced by a SyR motor can be expressed, in its general form, as follows:

$$
T=\frac{3}{2} p\left(\lambda_{d} i_{q}-\lambda_{q} i_{d}\right)
$$

where $p$ is the number of pole pairs, $i_{d}$ and $i_{q}$ are d-axis and q-axis currents, whereas $\lambda_{d}$ and $\lambda_{q}$ are d-axis and q-axis flux linkages which can be written as:

$$
\begin{aligned}
& \lambda_{d}=L_{d d} i_{d}+L_{d q} i_{q} \\
& \lambda_{q}=L_{d q} i_{d}+L_{q q} i_{q}
\end{aligned}
$$

In (2) and (3) $L_{d q}$ is the term which takes into account the cross-coupling effects (usually neglected in the analytical design), and $L_{d d}$ and $L_{q q}$ are the d- and q-axis inductances, sum of the magnetizing and leakage components:

$$
\begin{gathered}
L_{d d}=L_{d m}+L_{s} \\
L_{q q}=L_{q m}+L_{s}+L_{q-r i b}
\end{gathered}
$$

where $L_{s}$ is the leakage inductance, equal for both axis, and $L_{q-r i b}$ is the additional leakage inductance due to the flux short circuited via the iron ribs. From the vector diagram at steady state depicted in Fig. 1a, the internal power factor $i p f$, i.e. the cosine of the angle between the induced voltage $E$ and the current vector $I_{m}$, can be deduced:

$$
\text { ipf }=\cos \left(\phi_{i}\right)=\sin (\gamma-\delta)
$$

where $\gamma$ and $\delta$ are the current and the flux phase angles, respectively. Once the d-axis flux per pole is defined $\left(2 R_{r} L B_{g}\right)$, the tooth width $\left(w_{t}\right)$ and stator yoke $\left(l_{y}\right)$ can be sized imposing the desired iron flux density $B_{f e}$ :

$$
\begin{aligned}
l_{y} & =\frac{\pi}{2} \frac{R_{s}}{p} s r \cdot m r \\
w_{t} & =\frac{2 \pi R_{s}}{6 q p} s r \cdot m r
\end{aligned}
$$


where $q$ is the number of slots per pole per phase.

Regarding the rotor geometry design, the assumptions of 1) a uniform distribution of the equivalent rotor slots, 2) same permeance of the barriers and 3) total iron thickness along the $\mathrm{q}$-axis equal to the stator yoke thickness, allow to fully define the rotor and to calculate the q-axis magnetizing inductance without solving the equivalent magnetic circuit [18]. Consequently, the magnetizing components of both dand q-axis inductances $\left(L_{d m}\right.$ and $\left.L_{q m}\right)$ can be analytically calculated [18], [19] and expressed as function of geometrical parameters:

$$
\begin{gathered}
L_{d m}=\frac{\pi}{2} \mu_{0} k_{w}\left(\frac{N_{s}}{p}\right) \frac{s r R_{s} L}{k_{c} g} \\
\frac{L_{q m}}{L_{d m}}=\left(1-\frac{4}{\pi} \sum_{k=1}^{n} f_{i}^{2} \Delta \alpha_{i}\right)+\left(\frac{4}{\pi} \frac{p k_{c} g}{s r R_{s}} \sum_{k=1}^{n} \frac{s_{i}}{h_{i}} \Delta f_{i}\right)
\end{gathered}
$$

where $k_{c}$ is the Carter coefficient, $k_{w}$ is the winding factor, $N_{s}$ is the turns' number in series per phase, $f_{i}$ is the stator m.m.f averaged along the periphery of the rotor with intervals equal to the rotor pitches $\Delta \alpha_{i}$ (both shown in Fig. 2), $n$ is the number of flux barriers, $s_{i}$ and $h_{i}$ are the surface (in p.u. of the axial length) and the height of the i-th flux barrier, respectively (Fig. 2b). The d-axis current component can be inferred from the Ampere's law (when $i_{q}=0$ ):

$$
i_{d}=\frac{\pi}{3} \frac{k_{c} g}{\mu_{0}} \frac{p}{k_{w} N_{s}} B_{g}
$$

The q-axis component can be calculated knowing $i_{d}$ and the maximum current $I_{\max }$. Considering the motor geometrical dimensions and the correlation between cooling capability $k_{\text {cool }}$, total losses $P_{t}(12)$, and phase resistance $R_{p h}$ (13), the maximum current value $I_{\max }$ is calculated as in (14).

$$
\begin{gathered}
P_{t}=2 \pi R_{s} L k_{\text {cool }}=P_{j}+P_{f e}=3 R_{p h} I_{\text {max }}^{2}+P_{f e} \\
R_{p h}=3 N_{s}^{2} \frac{2 \rho_{c u}\left(L+L_{e w}\right)}{k_{f i l l} A_{\text {slot }}} \\
I_{\text {max }}=\frac{1}{3 N_{s}} \sqrt{\frac{k_{\text {fill }} A_{\text {slots }}}{2 \rho_{\text {cu }}\left(L+L_{\text {ew }}\right)}\left(2 \pi R_{s} L k_{\text {cool }}-P_{f e}\right)}
\end{gathered}
$$

In (13) $k_{\text {fill }}$ is the imposed slot fill factor, $\rho_{c u}$ is the copper resistivity, $A_{\text {slots }}$ and $L_{e w}$ are the slots area and the endwinding length which can be both calculated from the stator geometrical parameters. For low-speed operations of SyR machines, iron losses are negligible with respect to the Joule
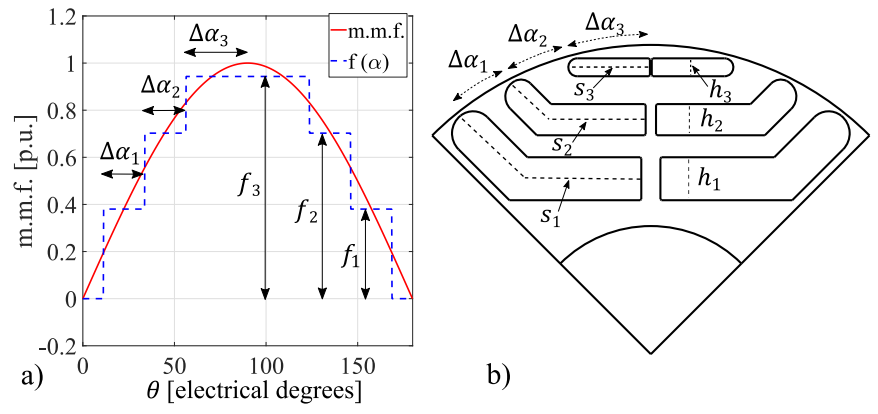

b)

Fig. 2. a) Stator q-axis m.m.f. b) Rotor parametrization. ones, and can be disregarded in the $I_{\max }$ computation [18], [19]. Conversely, considering a design scenario at constant total losses, the iron losses become significant as the speed increases, thus reducing the value of $I_{\max }$. The iron loss can be estimated considering the Steinmetz equation as in (15):

$$
P_{f e}=k_{f e} M_{f e}\left[k_{h} f^{\alpha} B_{f e}^{\beta}+k_{e}\left(f B_{f e}\right)^{2}\right]
$$

where $k_{f e}$ is a correction factor (usually between 1-2), $M_{f e}$ is the iron mass, $k_{h}$ and $k_{e}$ are the hysteresis and the eddy current coefficients, $\alpha$ and $\beta$ are exponential coefficients for the frequency and flux density, respectively, and $f$ is the electrical frequency. This formulation neglects the harmonic losses and assumes that the whole stator iron shares the same flux density level over one electrical period.

The other source of performance reduction, proportional to the speed, is the increment of the q-axis inductance due to the increment of the thicknesses of the structural iron bridges. A bigger $\lambda_{q}$ caused by the additional flux portion flowing via the iron ribs obviously implies a loss of torque and power factor. The influence on the q-axis inductance of the structural iron bridges, featuring different dimensions on each barrier, can be analyzed solving the q-axis equivalent magnetic circuit, supposing a certain saturation of each rib [28]. However, if all the iron bridges assume the same thickness and all of them are equally saturated, then the increment of the q-axis inductance due to the flux shunted by the ribs can be calculated as:

$$
L_{q-r i b}=\frac{4}{\pi i_{q}} N_{s} k_{w} w_{r i b} L B_{s a t}
$$

where $w_{r i b}$ is the total iron rib thickness (sum of the tangential and radial ones $w_{t r}+w_{r r} / 2$ ), as reported in Fig. 1b.

Given the complexity of the rotor structural behaviour, the design of the iron bridges, i.e. the selection of their thickness, positions and orientation along the barrier can only be properly performed via FEA. However, a simplified analytical formulation considering only the steady state centrifugal force $F_{c}(i)$ is commonly used [20], [29] to estimate the total iron bridge $\left(w_{\text {rib }}(i)\right)$ of the $i^{\text {th }}$ barrier:

$$
w_{r i b}(i)=\frac{k_{s} F_{c}(i)}{\sigma_{s} L}=\frac{k_{s}}{\sigma_{s} L} m_{f g}(i) R_{f g}(i) w_{m}^{2}
$$

where $k_{s}$ is a safety factor, $\sigma_{s}$ is the yield strength of the rotor lamination, $m_{f g}$ is the sum of the flux guide masses which has to be sustained by the $i^{t h}$ iron bridge, $R_{f g}$ is the center of gravity of the same mass, and $w_{m}$ is the mechanical speed. The calculated rib thickness increases going from the outermost to the innermost flux barrier because the mass which must be sustained increases in the same direction. As a consequence, to properly determine the variation of the q-axis inductance, an equivalent magnetic circuit should be adopted, because (16) assumes that the ribs have the same thickness. For such aim, an equivalent rib thicknesses $w_{\text {avg }}$ is calculated as average of the rib thicknesses of the $n$ flux barriers as follows:

$$
w_{\text {avg }}=\frac{1}{n} \sum_{i=1}^{n} w_{\text {rib }}(i)
$$

The worsening of the electromagnetic performance proportional to the equivalent bridge thickness $w_{\text {avg }}$ is an assumption 
that allows the estimation of q-axis rib inductance $L_{q-r i b}$ as in (16), where $w_{\text {rib }}=w_{\text {avg }} / 2$. This approximation allows a fast estimation of the performance reduction due to the speed rise without solving the q-axis equivalent magnetic circuit. This assumption will be validated in the next two sections.

\section{AnALyticAl Design Limits}

Considering the set of assumptions and constraints reported in Table I, and using the design equations described in the previous section, the dependencies of torque and power factor from the split and magnetic ratio are analyzed by means of contour plots in the $s r-m r$ design plane.

With the aim of evaluating the accuracy of the analytical design formulations, all the machine designs in the $s r-m r$ plane have been FE-simulated both at low $(1 \mathrm{krpm})$ and high speed $(50 \mathrm{krpm})$. Fig. 3 reports a comparison between the analytical and the FEA results in terms of average torque and internal power factor in the $s r-m r$ plane.

Both torque and power factor show relevant errors for low and high speed, although in the latter case the discrepancy is much higher.

Low speed designs, Fig. 3a and 3c, exhibit error that can be ascribed to:

- the saturation of the d-axis flux path (affecting $L_{d}$ ), which has been ignored in the analytical design stage since the iron permeability has been assumed to be infinite,

- the cross-coupling effect (expressed by the term $L_{d q}$ ), which has also been ignored during the analytical performance estimation.

While for high speed designs (Fig. 3b and 3d):

- the mismatch between the analytical and FE-computed iron losses

- the approximation in the $L_{q-r i b}$ computation

are further sources of error in the torque and power factor predictions. To confirm these causes of mismatch, further investigations are reported hereafter for each source of error. Fig. 4a shows the ratio between the analytical and FE calculation of $L_{d m}$, which is the d-axis saturation factor. The latter is higher for design solutions with low split and magnetic ratios, which correspond to the region where the torque error is higher. Fig. $4 \mathrm{~b}$ and $4 \mathrm{c}$ report the ratio between $L_{d q} \cdot i_{q}$ and $L_{d d} \cdot i_{d}$, which quantifies the cross-coupling in the design plane for

TABLE I

MACHINE PARAMETERS

\begin{tabular}{c|cc}
\multicolumn{1}{c||}{ Parameter } & Value & Units \\
\hline \hline Outer stator radius & 26.2 & $\mathrm{~mm}$ \\
\hline Stack length & 50 & $\mathrm{~mm}$ \\
\hline Pole pair & 2 & $/$ \\
\hline Cooling capability & 37000 & $\mathrm{~W} / \mathrm{m}^{2}$ \\
\hline Stator yoke flux density & 1.9 & $\mathrm{~T}$ \\
\hline Stator tooth flux density & 2.1 & $\mathrm{~T}$ \\
\hline Airgap thickness & 0.25 & $\mathrm{~mm}$ \\
\hline Lamination material & Vacodur 49 & $/ /$ \\
\hline Yield strength & 390 & $\mathrm{MPa}$
\end{tabular}
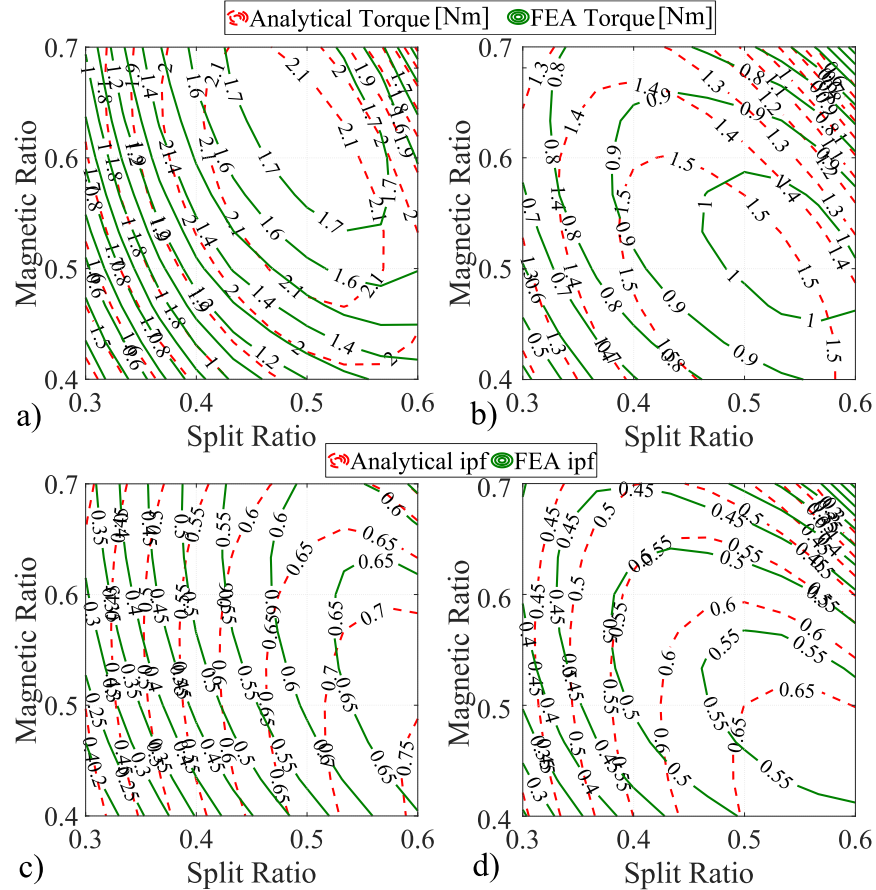

Fig. 3. Comparison between analytical and FE computation of torque (a, b) and internal power factor (c, d) at $1 \mathrm{krpm}(\mathrm{a}, \mathrm{c})$ and $50 \mathrm{krpm}(\mathrm{b}, \mathrm{d})$.

both low and high speeds. This term has been FE-evaluated adopting the frozen permeability approach reported in [30], [31]. As expected, in the design plane region where the cross coupling is more pronounced, the torque and power factor error is higher. At the higher speed, the cross-coupling terms are slightly higher with respect to the lower speed due to the increment of the iron area in common to both d- and q-axis fluxes. Regarding the iron losses, the analytical estimation clearly does not match with the FE computation, both in terms of numerical values and contour shape, as shown in Fig. 5a and $5 \mathrm{~b}$. This mismatch is due to the non uniform distribution of the stator iron flux density over the full $s r-m r$ plane as reported in Fig. 5c and 5d. These pictures show the first harmonic of the stator yoke and tooth flux densities (at $1 \mathrm{krpm}$ ) extracted from the FEAs. Fig. 5e and $5 \mathrm{f}$ confirm that approximating the increment of the q-axis inductance proportional to the average total bridge is acceptable being similar the contour shapes of $w_{\text {avg }}$ and $L_{q-r i b}$ FE calculated. Despite a qualitative match, there is a difference between analytical and FE inductance increment.

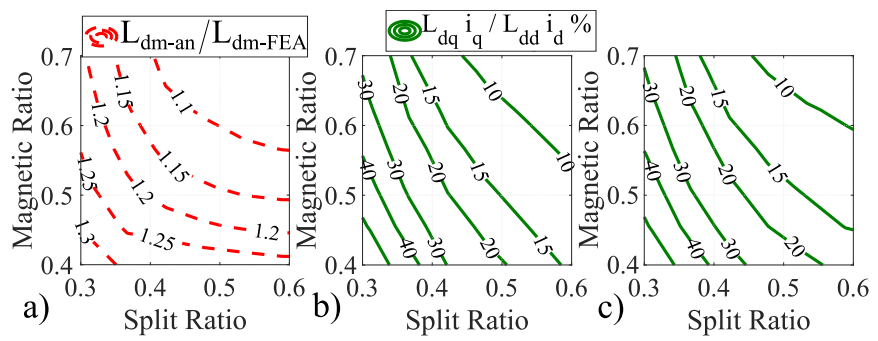

Fig. 4. a) Ratio between analytical and FE computation of $L_{d m}$, cross coupling effects at b) $1 \mathrm{krpm}$ and c) $50 \mathrm{krpm}$. 

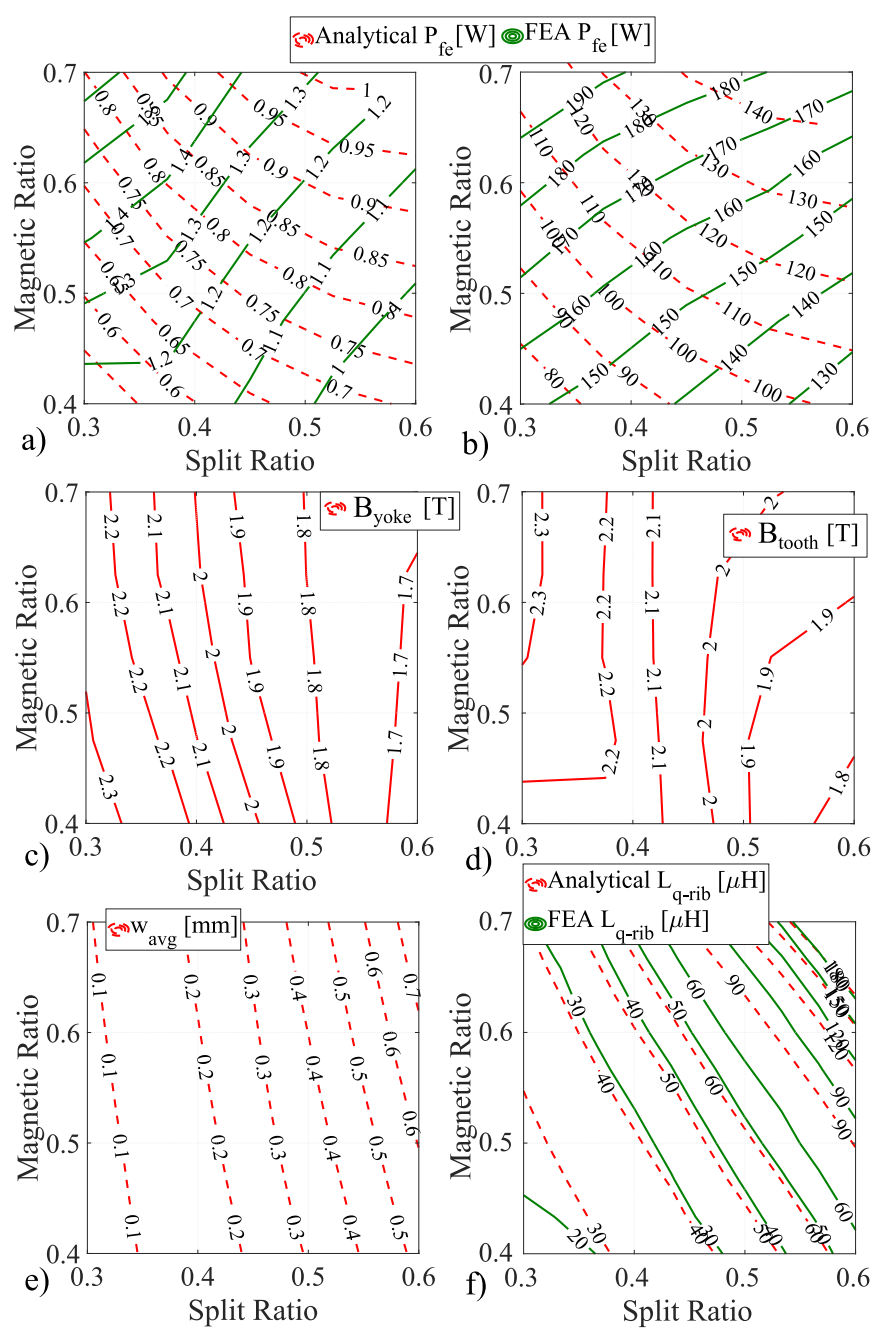

Fig. 5. Comparison between analytical and FE computation of iron losses at a) $1 \mathrm{krpm}$; b) $50 \mathrm{krpm}$. Average value of the flux density first harmonic component at $1 \mathrm{krpm}$ in c) stator yoke; d) stator tooth. e) Average total bridges at $50 \mathrm{krpm}$. f) Comparison between analytical and FE computation of $L_{q-r i b}$ at $50 \mathrm{krpm}$.

\section{OVERCOMING THE ANALYTICAL DESIGN LIMITS}

The downsides analyzed in the previous section are clearly due to the several approximations of the analytical model and could be easily overcome performing a FEA for each design solution in the $s r-m r$ plane. However, this becomes unreasonably expensive from a computational point of view and would nullify the advantage of using an analytical formulation in first instance. An interesting solution to this problem has been proposed in [19], where the authors FE-evaluate the design solutions at the corners of the $s r-m r$ plane. Using the FE-calculated values of the flux linkages, it is possible to adjust the analytical fluxes estimation and so torque and power factor. Although effective, this procedure does not allow to discern the root cause of the discrepancies between the analytical and FE results. In addition, it neglects the effect of the iron losses on the overall performance. In the following, a comprehensive procedure is proposed which is able to adjust the analytical-FE mismatch due to the saturation effects, increased iron losses and iron ribs incurring at high speeds. With the implemented iterative FE-adjustment algorithm, the

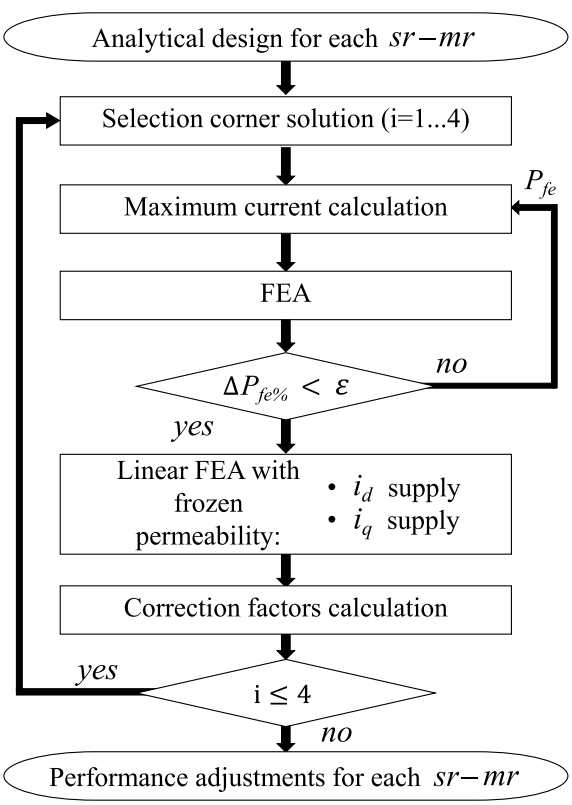

Fig. 6. Flowchart of the FE-adjustment procedure

causes of the discrepancies between analytical and FE results can be separately quantified. The flowchart shown in Fig. 6 summarizes the proposed approach which consists of the following steps.

- The analytical design is performed for all $s r-m r$.

- For each corner solution of the $s r-m r$ plane, the maximum current is calculated and a transient FEA is carried out so to calculate the iron losses. The latter are compared with the previous values used for the maximum current calculation. If the relative error lies within a predefined threshold, the algorithm proceeds to the next step, otherwise a further FEA is performed updating the iron loss value for the maximum current computation.

- Once the correct $i_{d}, i_{q}$ currents are known, two linear FEAs are carried out with the permeability frozen to the values obtained from the previous non-linear FE simulation. By supplying only $\mathrm{d}$ - or q-axis current component is then possible to split both d- and q-axis inductances into two components (e.g. $L_{d d}$ and $L_{d q}$ ), allowing the full characterization of the cross coupling term and the saturation effect. The slot leakage inductance is also calculated as the difference between the inductance, estimated with the flux linkage, and the integration of the airgap flux density.

- After the two linear FEAs are performed, five corrections factors are evaluated: $k_{P f e} k_{L d m}, k_{L q}, k_{L d q}$ and $k_{L s}$ accounting for the modelling error of the iron losses, saturation and cross-saturation, and q-axis inductance of the iron ribs.

- Once this iterative procedure is performed for each corner solutions, then the correction factors are extended to the full $s r-m r$ plane using a linear interpolation.

Torque and internal power factor values can be then recalculated according to the following equations:

$$
\begin{aligned}
T_{a d j}=\frac{3}{2} p\left[\left(k_{L_{d m}} L_{d m} i_{d}+k_{L_{d q}} L_{d q} i_{q}\right) i_{q}-\right. \\
\left.\quad-\left(k_{L_{d q}} L_{d q} i_{d}+k_{L_{q}}\left(L_{q m}+L_{q-r i b}\right) i_{q}\right) i_{d}\right]
\end{aligned}
$$




$$
\begin{aligned}
& i p f_{a d j}=\sin \left[\arctan \left(\frac{i_{q}}{i_{d}}\right)-\right. \\
&\left.-\arctan \left(\frac{\left(k_{L_{q}}\left(L_{q m}+L_{q-r i b}\right)+k_{L_{s}} L_{s}\right) i_{q}+k_{L_{d q}} L_{d q} i_{d}}{\left(k_{L_{d m}} L_{d m}+k_{L_{s}} L_{s}\right) i_{d}+k_{L_{d q}} L_{d q} i_{q}}\right)\right]
\end{aligned}
$$

The application of this FE-adjustment procedure is shown in Fig. 7 in terms of torque and internal power factor contours in the $s r-m r$ plane for two different speeds (1 and 50 $\mathrm{krpm})$. It is worth underlining the good agreement between the analytical adjusted results and the FEA ones. In terms of torque, the average error is approximately $1.7 \%$ over the whole $s r-m r$ plane. The maximum torque error is about $20 \%$ and it is always located away from the maximum torque or power factor designs which is the area of final interest. A lower error is experienced by the ipf with an average value of $0.7 \%$ over the whole $s r-m r$ plane and a maximum of about $10 \%$. The good agreement at low speed is due to the adjustment of the modeling errors of both magnetizing inductances $\left(L_{d m}, L_{q m}\right)$ and the neglected saturation and cross saturation phenomena (acting on $L_{d m}, L_{d q}$ respectively). These aspects are corrected via the coefficients $k_{L d m}, k_{L q m}$ and $k_{L d q}$; Fig. $8 \mathrm{a}$ and $8 \mathrm{~b}$ underline the good agreement between the adjusted and the FEA magnetizing inductances while Fig. 4b reports the cross-coupling effect in the whole $s r-m r$ plane. When considering high speed designs, the influence of the modelling error of the iron losses and iron ribs inductance becomes more relevant therefore their adjustment is fundamental to improve the performance estimation accuracy. Fig. 8c reports an evident improvement of the iron losses estimation compared to the pure analytical approach shown in Fig. 5a,b. Fig. 8d confirms that the proposed iterative procedure allows bridging the gap between analytical and FE estimated q-axis inductance increment due to the iron ribs shown in Fig. $5 \mathrm{f}$.
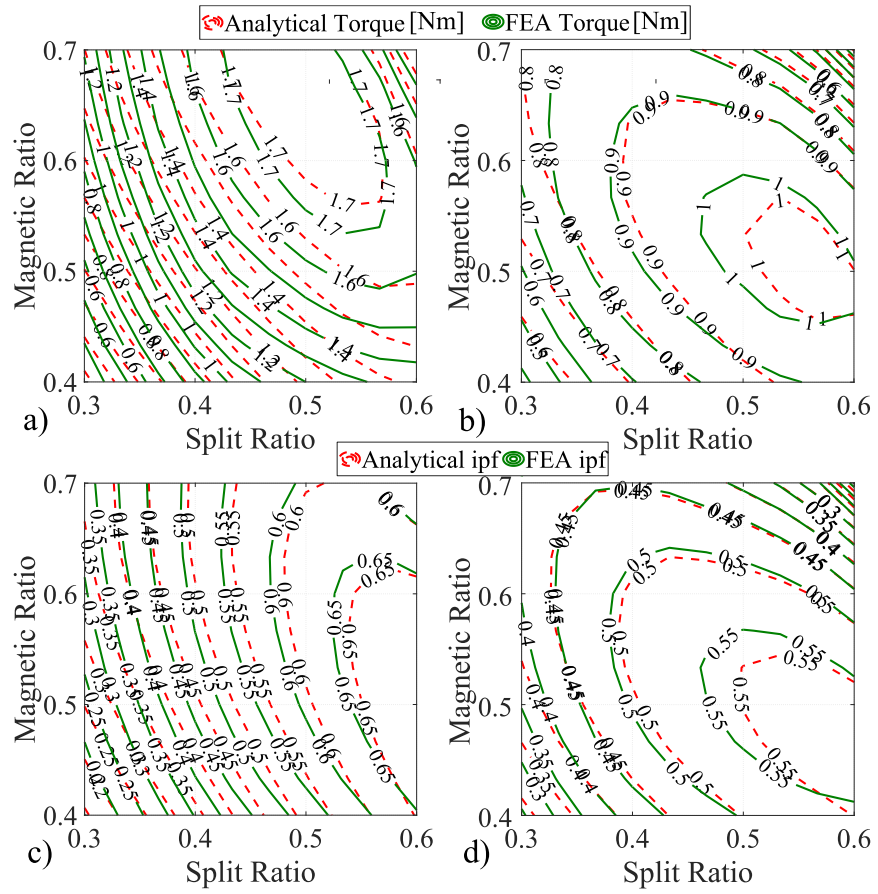

Fig. 7. Comparison between analytical and FE computation of torque $(\mathrm{a}, \mathrm{b})$ and $i p f(\mathrm{c}, \mathrm{d})$ at $1 \mathrm{krpm}(\mathrm{a}, \mathrm{c})$ and $50 \mathrm{krpm}(\mathrm{b}, \mathrm{d})$.
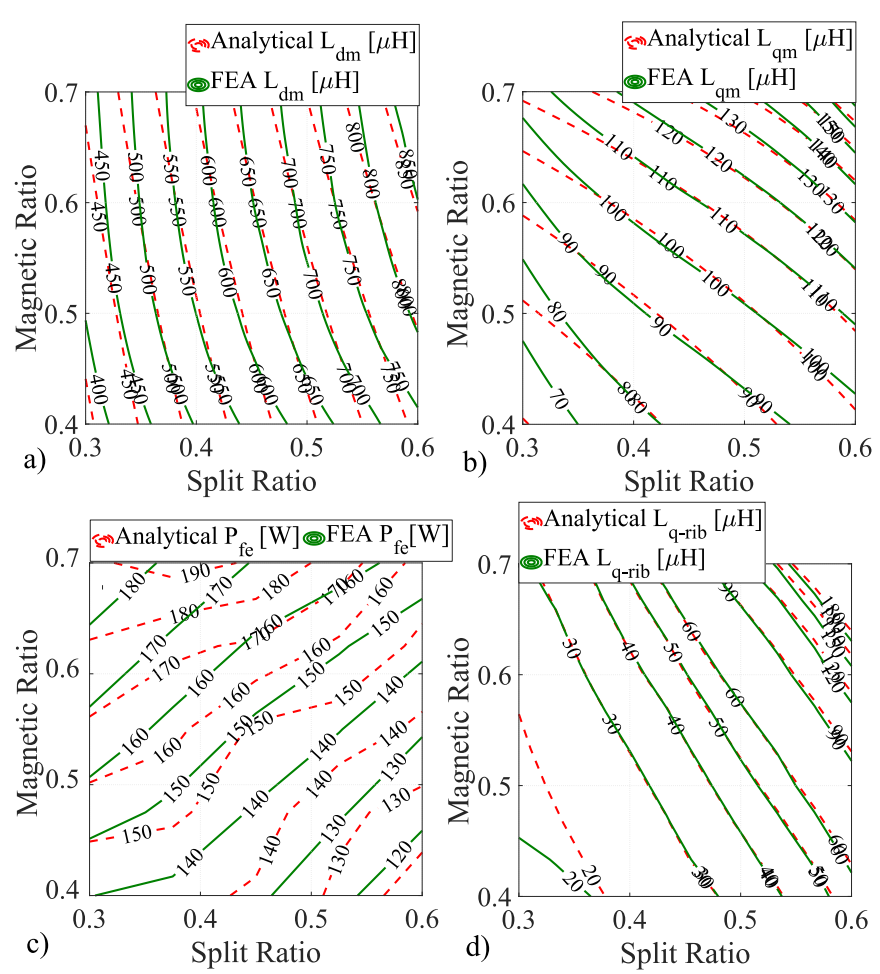

Fig. 8. Comparison between analytical and FE computation of the d-axis (a) and q-axis (b) magnetizing inductances, iron losses (c) and $L_{q-r i b}$ (d) at 50 $\mathrm{krpm}$

\section{INFLUENCE OF THE HIGH-SPEED LIMITING FACTORS}

Although the errors between the analytically estimated performance and the FE ones are not null, the good qualitative match of the contour shapes allows using the presented design approach to draw general design guidelines for high speed SyR machines. In this section, the described design procedure is applied to the machine whose main dimensions and design assumptions are reported in Table I and considering different maximum speeds. As the speed increases, analyzing torque and power factor contours changes and how the optimal performance decreases, as well as how the optimal geometry evolves is deemed to be very interesting. The outlined design routine also consents to separately analyze the effect on the performance due to the increased iron ribs and iron losses incurring at high speeds. Fig. 9 depicts the maximum torque and the power factor in the same operating condition as a function of the speed for three different cases:

- ignoring the iron losses in the maximum current computation in eq. (14) (blue line);

- ignoring the structural limitation, i.e. neglecting the iron rib thickness and the relative q-axis inductance increment (red line);

- considering both high speed limiting design aspects (green line).

As expected, both optimal torque and power factor decrease as the speed increases when both limiting design factors are considered. The torque reduction from the lowest to the highest speed is about $66 \%$ while the power factor reduction is much lower, i.e. circa $33 \%$ (almost halved). As the speed increases, both iron losses and structural ribs negatively affect the torque, with the first one having a bigger impact. Conversely, the 

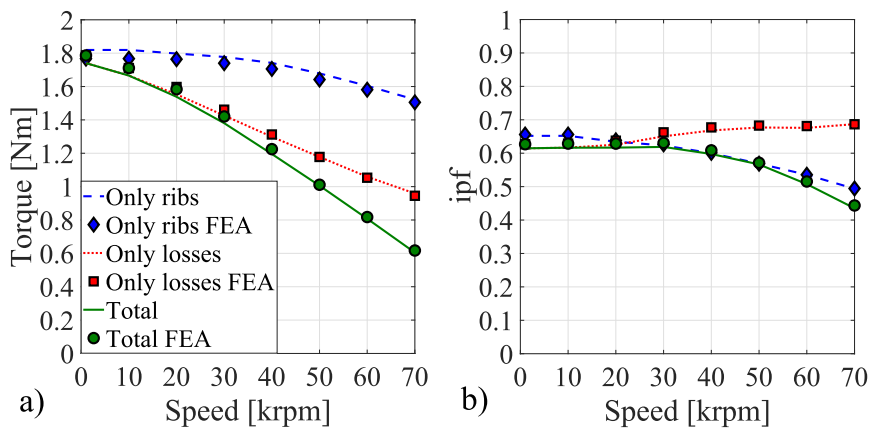

Fig. 9. Maximum torque (a) and internal power factor at the maximum torque (b) as a function of the speed

ipf is improved by the effect of iron losses whereas it is reduced by the presence of iron ribs. The latter effect prevails on the first one and so the ipf globally decreases. If the (total) torque reduction is less than the speed increment, then the mechanical output power obviously increases, as shown in Fig. 10, otherwise above a certain speed, the output power decreases. Above this threshold speed, it is not convenient to further increase the operating speed, so the maximum power capability of the SyR machine is reached. Fig. 10 also reports the maximum mechanical power achievable considering the iron ribs and iron losses effects separately. It is worth to underline that the maximum power point when considering only the structural limitation is higher with respect to the case where both structural and total loss constraints are considered. Fig. 9 and 10 also report the performance of the optimal machines evaluated via FEAs (shown with the markers). An excellent agreement is evident and this indirectly validates the proposed design approach. Fig. 11 reports the optimal design variables (i.e $s r$ and $m r$ ) as a function of the speed. The split ratio slightly increases with the speed while the magnetic ratio monotonically decreases when both limiting design factors are taken into account. When the latter are considered separately, the rise of the iron losses causes an increment of the optimum split ratio and a decrement of the optimal magnetic ratio. Conversely, the same design variables show the opposite behaviour if only the ribs effect is considered. Therefore, as the speed increases, the combination of these two effects slightly increases the split ratio, whereas reduces the magnetic ratio.

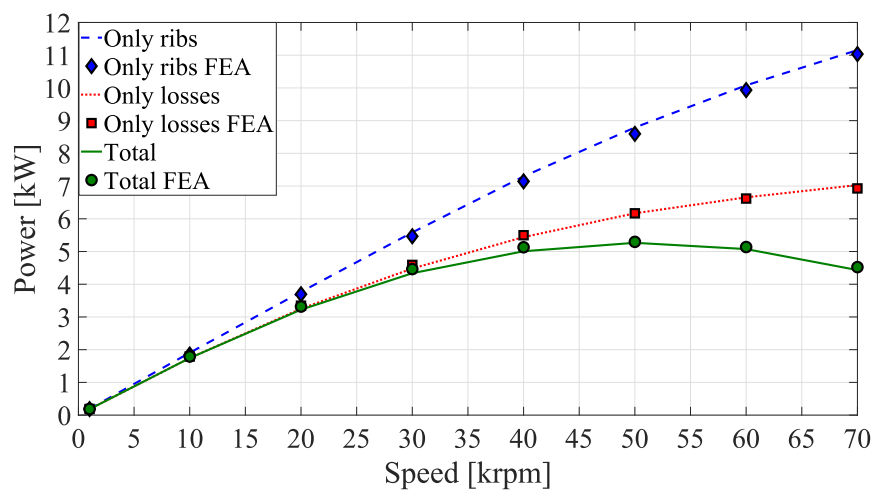

Fig. 10. Power as a function of the speed
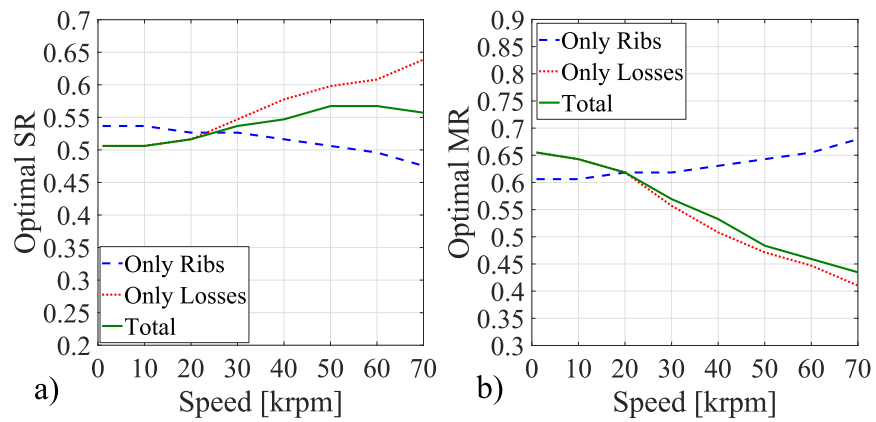

Fig. 11. Optimal sr (a) and $\mathrm{mr}$ (b) as a function of the speed

\section{RESULTS DISCUSSION}

In order to investigate in detail the trends shown in Fig. 9 and 11 , in the following torque and power factor loci in the design plane for three different speeds are analyzed. Such results are obtained considering the influence of iron losses and iron ribs separately.

\section{A. Iron Losses influence}

Fig. 12 shows three constant torque loci calculated considering only the effect of the stator iron losses. It is clear that the maximum torque designs ( $\square$ @ $1 \mathrm{krpm}, \bullet @ 40 \mathrm{krpm}$, @ 70krpm) move towards the bottom-right side of the design plane and so the optimum (torque wise) split ratio increases whereas the optimum magnetic ratio decreases. This trend is caused by the reduction of the q-axis current. In fact, the maximum torque location is the compromise among the competitive needs of maximizing the magnetic anisotropy $\left(L_{d}-L_{q}\right)$, the magnetizing current $i_{d}$ and the q-axis current $i_{q}$. The first two $\left(L_{d}-L_{q}\right.$ and $\left.i_{d}\right)$ do not depend on the speed if the iron ribs effect is neglected, whereas the third one $\left(i_{q}\right)$ depends on the slot areas (unaffected by the speed) and the iron losses. As the speed increases, the iron losses rise reduces the q-axis current component, as shown in Fig. 13a, 13b and 13c. Consequently, the influence in the torque generation $\left(\left(L_{d}-L_{q}\right) i_{d} i_{q}\right)$ of the qaxis current weakens and the maximum torque design moves towards the maximum magnetic anisotropy, i.e. higher split ratio and low magnetic ratio, as also shown in Fig. 13d, 13e and 13f. The iron losses contours for 40 and $70 \mathrm{krpm}$ along with the stator iron mass contour are reported in Fig. 13g, $13 \mathrm{~h}$ and $13 \mathrm{i}$. Since the iron stator surface does not change with the speed, Fig. 13g also reports the maximum torque design for each considered speed. The maximum torque design moves towards the zone of the design plane with lower stator

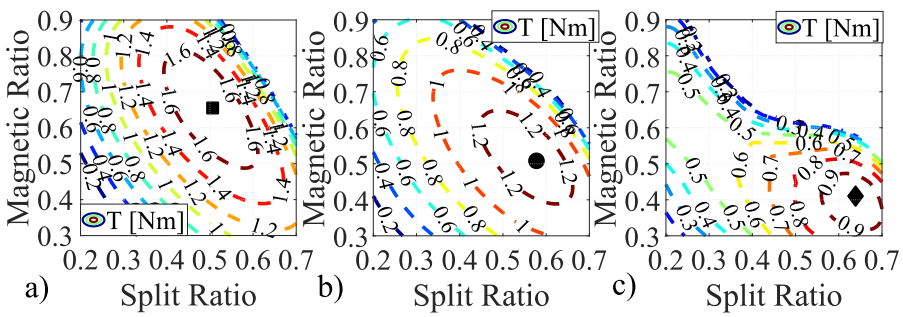

Fig. 12. Constant torque loci in the plane $s r-m r$ obtained considering only the iron losses effect at: a) $1 \mathrm{krpm}, \mathrm{b}) 40 \mathrm{krpm}$, c) $70 \mathrm{krpm}$. 

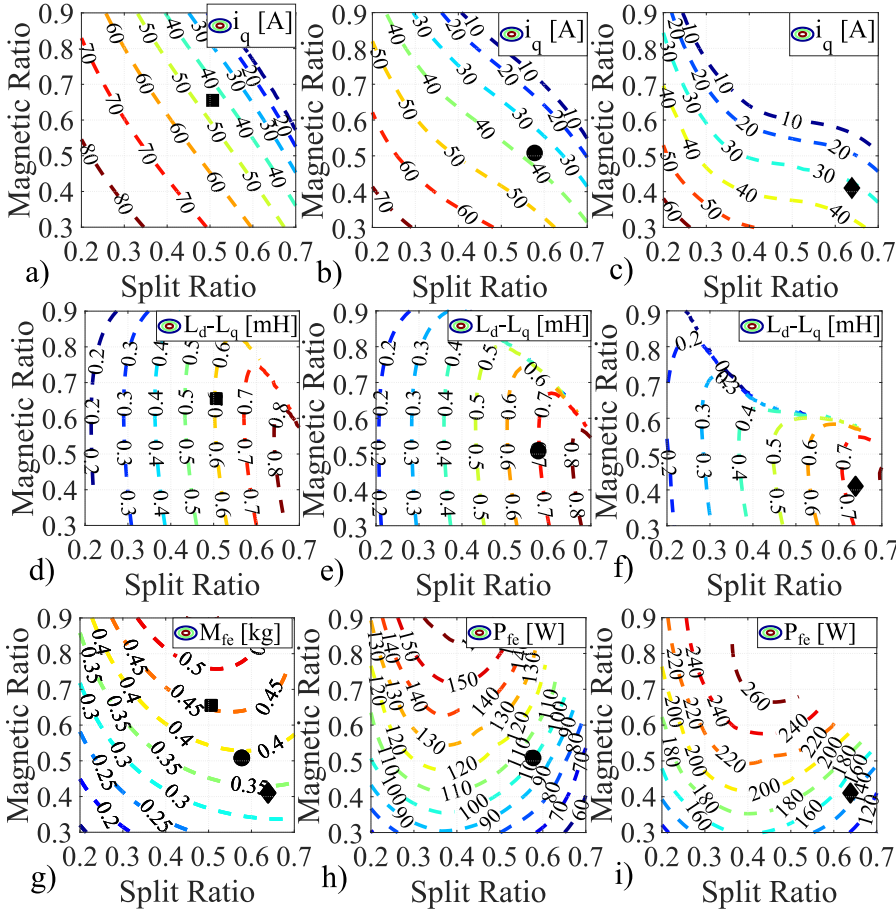

Fig. 13. Constant $i_{q}(\mathrm{a}, \mathrm{b}, \mathrm{c})$ and $L_{d}-L_{q}(\mathrm{~d}, \mathrm{e}, \mathrm{f})$ loci considering only the iron losses effect at: $1 \mathrm{krpm}(\mathrm{a}, \mathrm{d}), 40 \mathrm{krpm}(\mathrm{b}, \mathrm{e}), 70 \mathrm{krpm}(\mathrm{c}, \mathrm{f})$; constant stator core mass loci (g) and iron losses at $40 \mathrm{krpm}(\mathrm{h})$ and $70 \mathrm{krpm}(\mathrm{i})$.

iron surface and so lower iron losses which in turn means higher q-axis current and bigger slots area. The increment of the ipf corresponding to the maximum torque design can be easily explained considering Fig. 14. The constant ipf loci are slightly affected by iron losses and, since the direction of the maximum torque designs corresponds to the direction towards higher magnetic anisotropy, also the ipf increases.

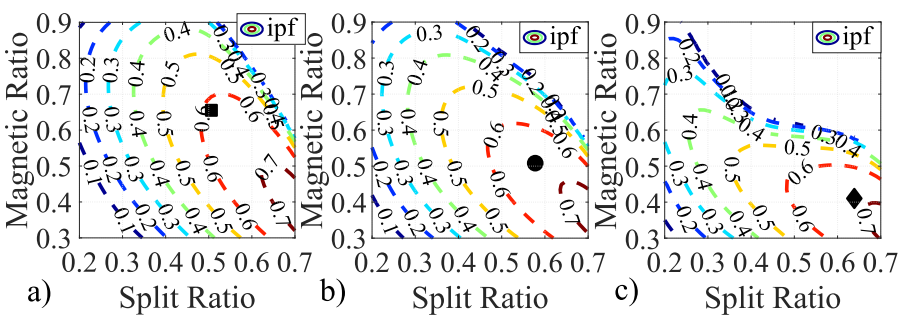

Fig. 14. Constant ipf loci in the plane $s r-m r$ obtained considering only the iron losses effect at: a) $1 \mathrm{krpm}$, b) $40 \mathrm{krpm}$, c) $70 \mathrm{krpm}$.

\section{B. Structural ribs influence}

Fig. 15 reports the constant torque loci obtained considering only the iron ribs effect for three different speeds $(1,40$ and $70 \mathrm{krpm}$ ). The maximum torque designs (ם @ 1 krpm, • @ 40krpm, @ 70krpm) slightly move towards the top-left corner of the design plane because in the same direction the average total bridge $w_{\text {avg }}$ decreases (as also shown in Fig. 11). In fact, lower split ratio $s r$ implies lower rotor radius and so lower centrifugal forces which reduce the required rib $w_{\text {avg }}$, as reported in Fig. 16a.

Fig. $16 \mathrm{~b}$ and $16 \mathrm{c}$ report the percentage variations of torque (decrements) and q-axis inductance (increment) with respect to

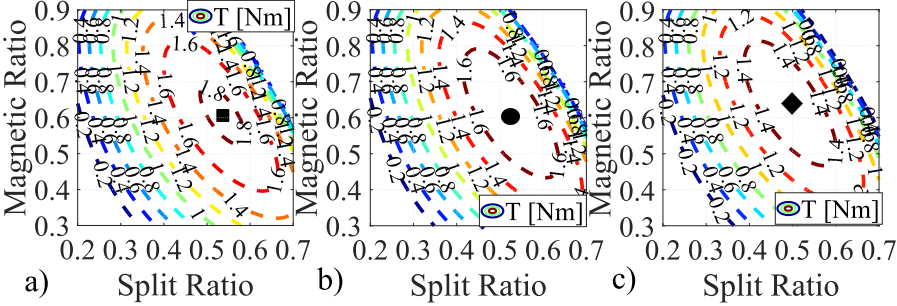

Fig. 15. Constant torque loci in the plane $s r-m r$ obtained considering only ribs effect at: a) $1 \mathrm{krpm}$, b) $40 \mathrm{krpm}$, c) $70 \mathrm{krpm}$.

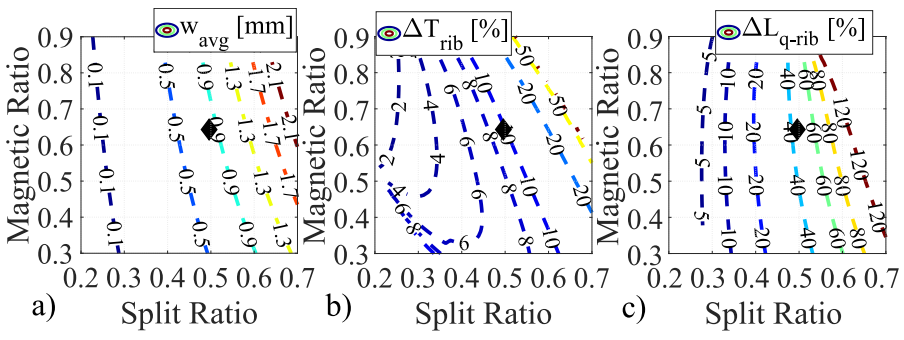

Fig. 16. Constant locus in the design plane $s r-m r$ obtained considering only the ribs influence at $70 \mathrm{krpm}$ on a) average total ribs, b) torque decrement, c) q-axis inductance increment.

the design with no ribs. It is worth noticing that the influence of the iron ribs is heavier on the q-axis inductance than on the torque; in fact, for a given couple of design variables $s r$ and $m r, \Delta L_{q-r i b} \%$ is higher than $\Delta T_{r i b} \%$. This behaviour can be justified analyzing eq. (16), which highlights that $L_{q-r i b}$ is proportional to $w_{\text {avg }}$ and inversely proportional to $i_{q}$; while $w_{\text {avg }}$ increases going from the bottom-left to the upper-right corner of the design plane (Fig. 16a), the q-axis current increases in the opposite direction (as shown in Fig. $13 \mathrm{~b}$ ), therefore $i_{q}$ intensifies the effect of $w_{\text {avg }}$ in the $L_{q-r i b}$ increment. The high increase of the q-axis inductance causes a significant power factor drop as reported in Fig. 9b. Although the shape of the constant ipf loci does not change significantly with the speed (as shown in Fig. 17), its value is greatly reduced. It can be stated that the ribs presence affects the power factor more than the torque.

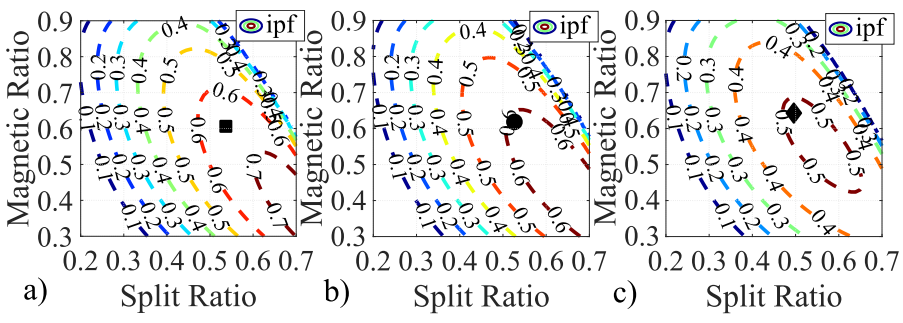

Fig. 17. Constant ipf loci in the plane $s r-m r$ obtained considering only iron ribs effect at: a) $1 \mathrm{krpm}$, b) $40 \mathrm{krpm}$, c) $70 \mathrm{krpm}$.

\section{Optimal machines}

Fig. 18a, 18b and 18c report the rated flux density distribution of the optimal machines obtained considering separately the influence of iron ribs (a), the iron losses (b) and both limiting phenomena (c) for 4 different speeds $(1,20,50$ and $70 \mathrm{krpm}$ ). The considerations described in the previous two sections are visually confirmed especially regarding the split 


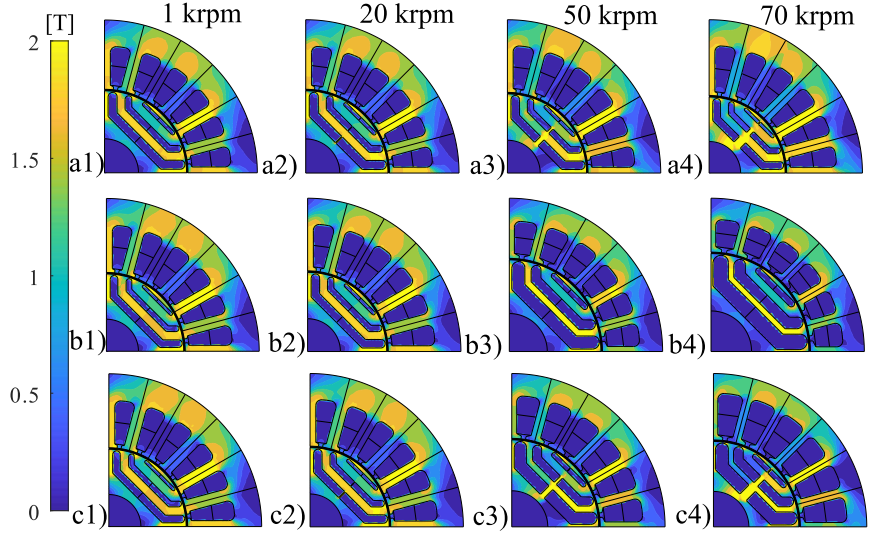

Fig. 18. Optimal machines obtained considering: (a) only iron ribs, (b) only iron losses and (c) both aspects at different speeds.

ratio. Regarding the magnetic ratio, this affects the dimensions of stator teeth and yoke and rotor flux guides (and so flux barrier thicknesses). Table II reports the main geometrical parameters of the optimal machines. Analysing both Fig. 18 and Table II, the following considerations can be done.

- The width of the flux barriers increases with the speed if only the iron losses are taken into account, whereas a quasiconstant trend can be inferred when only the effect of iron ribs is considered.

- Similar considerations can be drawn for the tooth width. The reduction of the optimal magnetic ratio depicted in Fig. $11 \mathrm{~b}$ (for the total and only losses cases) reduces the airgap flux density, i.e. the flux per pole and so the required tooth width for a fixed flux density $B_{f e}$. Conversely, being the magnetic ratio almost constant, if only the iron ribs effect is considered, also the tooth width of the optimal machine does not change significantly. Similar trends are experienced by the stator yoke thickness.

These considerations are clearly dependent on the selected lamination material which influences the balance between structural and iron losses effects.

It is important to underline that machines obtained considering only the losses influence do not represent a real case, since the structural iron ribs are necessary to guarantee the rotor integrity under high-speed operations. Conversely, the results

TABLE II

OPTIMAL MACHINE GEOMETRICAL PARAMETERS (IN MM)

\begin{tabular}{c||c|c|c|c|c} 
Design & Variable & $\mathbf{1} \mathbf{~ k r p m}$ & $\mathbf{2 0} \mathbf{~ k r p m}$ & $\mathbf{5 0} \mathbf{~ k r p m}$ & $\mathbf{7 0 k r p m}$ \\
\hline \hline \multirow{5}{*}{ Only ribs } & $w_{t}$ & 2.01 & 2.00 & 1.97 & 1.96 \\
& $l_{y}$ & 4.45 & 4.44 & 4.37 & 4.36 \\
& $h_{\text {air }-1}$ & 1.53 & 1.53 & 1.43 & 1.30 \\
& $h_{\text {air }-2}$ & 1.11 & 1.11 & 1.04 & 0.94 \\
& $h_{\text {air }-3}$ & 0.64 & 0.64 & 0.59 & 0.54 \\
\hline \multirow{5}{*}{ Only loss } & $w_{t}$ & 2.05 & 1.97 & 1.74 & 1.61 \\
& $l_{y}$ & 4.54 & 4.37 & 3.86 & 3.58 \\
& $h_{\text {air }-1}$ & 1.28 & 1.43 & 2.22 & 2.62 \\
& $h_{\text {air }-2}$ & 0.93 & 1.04 & 1.61 & 1.90 \\
& $h_{\text {air }-3}$ & 0.53 & 0.59 & 0.92 & 1.09 \\
\hline \multirow{5}{*}{ Total } & $w_{t}$ & 2.04 & 1.97 & 1.69 & 1.49 \\
& $l_{y}$ & 4.54 & 4.37 & 3.75 & 3.31 \\
& $h_{a i r-1}$ & 1.28 & 1.43 & 2.06 & 2.20 \\
& $h_{\text {air }-2}$ & 0.93 & 1.04 & 1.49 & 1.59 \\
& $h_{\text {air }-3}$ & 0.53 & 0.59 & 0.86 & 0.91
\end{tabular}

obtained neglecting the effects of iron losses can be considered feasible high-speed machine designs. In fact, the higher iron losses can be effectively managed (within reasonable limit) improving the cooling system capability as the speed increases. In any case, the optimal geometry identified with the proposed design approach needs a structural FE refinement stage. The location and distribution of the iron ribs along the barriers need to be optimized keeping the total iron bridge thickness per barrier as close as possible to the analytical estimated values. By doing so, the average torque would not change being not affected by the ribs position along the barrier but mainly by their thickness [32].

\section{Thermal assessment}

The proposed design procedure imposes the total stator losses to be constant, therefore the Joule losses (always calculated at $130^{\circ} \mathrm{C}$ ) are reduced as the iron losses increase with the design speed. This assumption allows to use the same cooling system for the whole set of designed machines therefore leading to a comparison on a fair basis. Although the optimal machines have the same total stator losses, they feature different loss distributions, therefore the machine thermal behaviour is envisaged to change as the design speed increases. In fact, machines with higher Joule losses experience higher winding temperatures as these are more difficult to be extracted with respect to the stator iron losses. These considerations are confirmed by the green lines in Fig. 19a reporting the hot-spot winding and average stator iron temperatures calculated with the commercial suite [33] for the optimal machines. Fig. 19b shows the trends of the Joule and stator iron losses.

On the contrary, if only the Joule losses are considered constant during the design procedure (dotted blue lines in Fig. 19b), the overall stator losses increase with the design speed as a consequence of the increased iron losses, leading to a rise of the winding temperature as depicted by the blue dotted lines in Fig. 19a. The rise of the winding temperature when constraining only the Joule losses is not massive due to the important increment of the power absorbed by the coolant as shown in Fig. 19c. Adopting a constant stator losses scenario guarantees obtaining more conservative designs being the winding temperature always within reasonable margin and

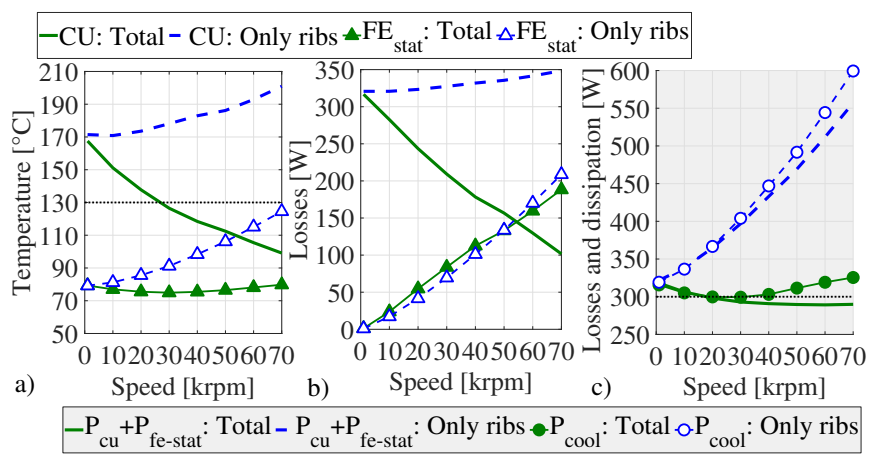

Fig. 19. a) Hot-spot winding and average stator iron temperatures, b) copper and stator iron losses, c) total stator losses and coolant absorbed power, as function of the speed for machines designed at constant total stator losses (Total) and constant Joule losses (Only ribs). 
the coolant absorbed power invariant as the design speed increases (green marked line in Fig. 19c).

\section{EXPERIMENTAL RESULTS}

The proposed hybrid design approach and subsequent considerations have been validated with experimental tests on an existing prototype, whose first variant was presented in [22]. The 5kW-50krpm machine, whose details are reported in Table I, was designed with a multi-objective optimization algorithm targeting the average torque and the torque ripple using different lamination materials. Fig. 20 reports a comparison between the optimal designed machine and the prototype, in terms of position in the $s r-m r$ plane (20a) and overall geometry (20b). The prototype has a split ratio and magnetic ratio of 0.58 and 0.42 , respectively, while the optimal design has $s r=0.56$ and $m r=0.48$. Although not identical, these two machines are very similar, and for this reason the existing prototype has been used to validate the presented design methodology.

The rotor structural design, i.e. the positioning of the iron ribs, was performed via a structural sensitivity FEA and the cross section of the manufactured machine is reported in Fig. 21d. The total rib thicknesses per barrier are equal to the ones calculated with the proposed analytical approach (since it was designed using the same analytical mechanical formulation). In particular the outermost barrier shows higher tangential iron ribs with respect to the designed one, in order to avoid the manufacturing of the respective radial rib (whose width is too close to the mechanical tolerances). The final radial iron ribs of the middle and innermost barrier are rotated and splitted in two as shown in Fig. 20 b.

Fig. 21c shows the experimental test set-up consisting of two identical SyR motors mechanically coupled (Fig. 21b) whose cross-section of the laminations stack is shown in Fig. 21d, a 20-kHz back-to-back IGBT 2-level converter fed by a dc voltage source (270V) and a dSPACE 1006 board (Fig. 21a) where the vector control strategy is implemented. Two different experiments have been performed, the first one aimed at identifying the flux-current relationship with the method presented in [34], while the second aimed at verifying the dynamic behaviour of the system at the maximum speed. In the former, several combinations of $i_{d}$ and $i_{q}$ have been considered. During the magnetic model identification test, one machine is speed controlled, whereas the other one,

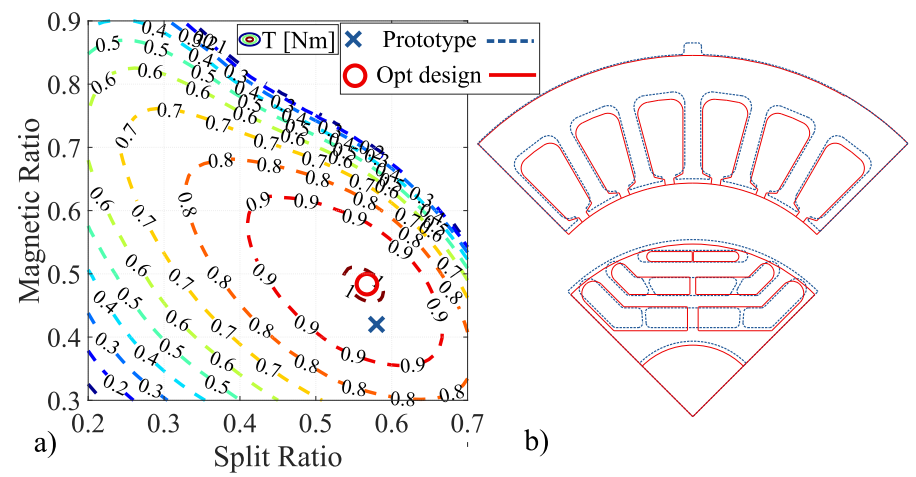

Fig. 20. Comparison between optimal designed machine and actual prototype.

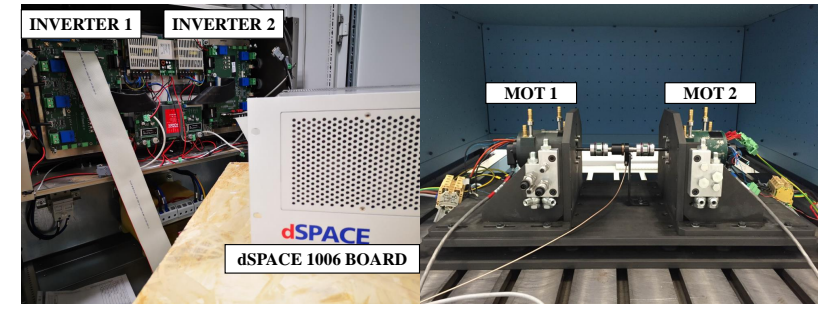

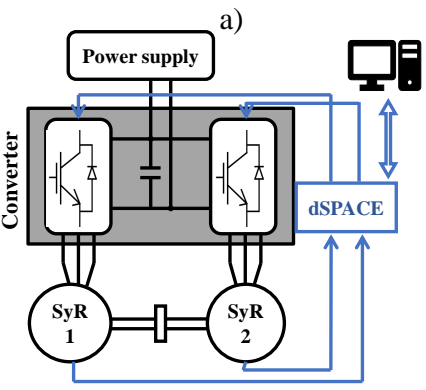

c) b)

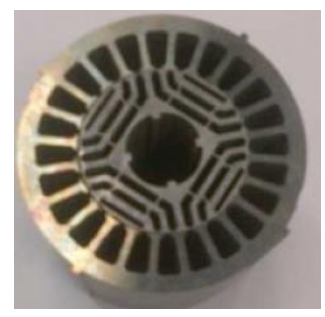

d)
Fig. 21. a) Inverter and dSpace board , b) Back-to-back motors, c) Experimental set-up layout, d) Top view of the laminations stack.

whose model has to be identified, is torque controlled. The identification tests performed on the prototype machine have shown a non-negligible mismatch between the experimental and FE-computed fluxes leading to an electromagnetic torque lower $(0.7 \mathrm{Nm})$ with respect to the $\mathrm{FE}$ one $(0.99 \mathrm{Nm})$, as reported in Fig. 22a. This discrepancy can be mainly ascribed to the manufacturing tolerances. In fact, when simulating a rotor geometry considering the worst case scenario in terms of manufacturing tolerances (iron ribs increases of $0.05 \mathrm{~mm}$ ),
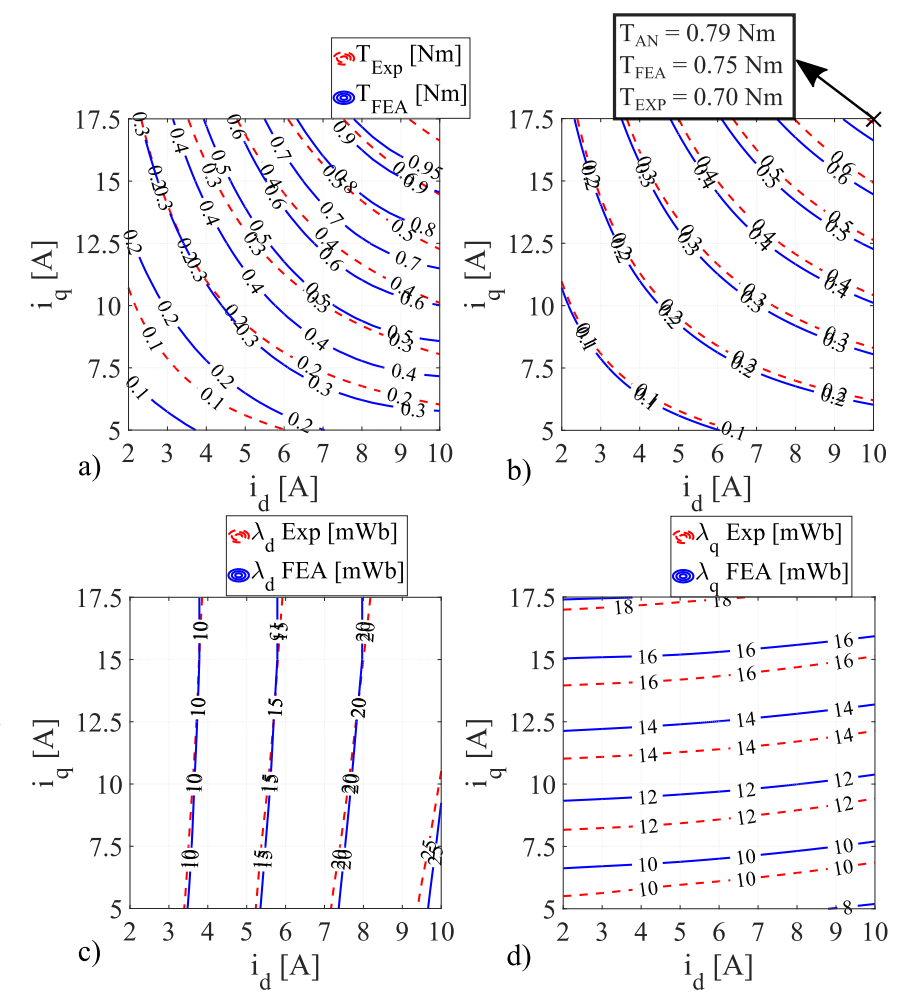

Fig. 22. (a,b) FE-computed torque vs experimental one a) neglecting the mechanical tolerances b) considering the mechanical tolerances; $(c, d)$ Magnetic identification in the $i_{d}-i_{q}$ plane $(\mathrm{a}, \mathrm{b})$. 

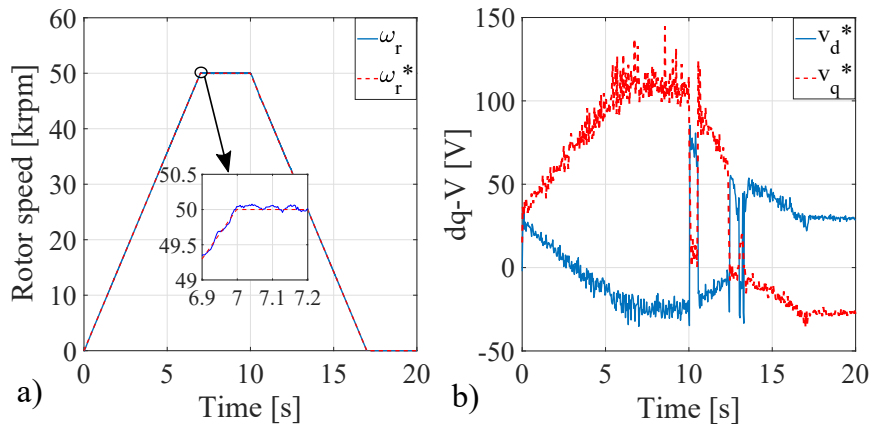

Fig. 23. Experimental speed test: a) reference speed and rotor speed; b) dq reference voltages.

then the error becomes much smaller, as reported in Fig. $22 \mathrm{c}$ and $22 \mathrm{~d}$. These sub-figures highlight a good agreement between the measured $\mathrm{d}$ - and $\mathrm{q}$-axis fluxes and the ones FE-calculated. Consequently, a good match is also achieved in terms of average torque as reported in Fig. 22b. The remaining mismatch between FE and experimental q-axis flux, which leads to the torque mismatch reported in Fig. 22b, can be ascribed to several reasons, e.g. the residual geometric differences between the prototype and the FE model, different magnetic behaviour (in terms of BH curve) of the material. Reevaluating the performance with the analytical model leads to a torque of $0.79 \mathrm{Nm}$ compared to the FE one of $0.75 \mathrm{Nm}$ and the experimental one of $0.7 \mathrm{Nm}$, as reported in the inset of Fig. 22b. In the same operating condition, the FE-computed internal power factor is 0.41 whereas the experimental one is 0.40. Fig. 23a shows the result of an acceleration test from zero to $50 \mathrm{krpm}$ without load torque, whereas Fig. 23b reports the reference voltages during the same test.

\section{CONCLUSION}

In this work an improved design approach for high speed synchronous reluctance machines based on an analytical model has been proposed. This is able to fully consider the high speed limiting design factors, i.e. the increasing structural limitation and iron losses. The accuracy of the analytical model has been compared with the FE results and a detail analysis of the roots of their mismatch has been investigated at both low and high speeds. The saturation of the d-axis flux path, the cross-saturation, the iron losses and the q-axis iron ribs inductance have been identified to be the main causes of inaccuracy in the analytical performance estimation. A new computational efficient approach has been then proposed in order to adjust the identified pitfalls of the analytical model. Indeed, FE-simulating a subset of design solutions is possible to correct the mismatch between analytical and FE performance for the whole set of design solutions. After the full $\mathrm{FE}$ validation, the proposed design method has been used to study the limiting phenomena taking place as the operating speed increases. It has been shown that both iron ribs and iron losses increment limit the maximum power that can be achieved by increasing the speed. Indeed, above a certain value is definitely not convenient to further increase the speed. This speed threshold is higher if only the structural limitations are considered letting the overall losses increase (implicitly assuming an increment of the cooling capability with the speed). Considering the maximum torque design the trends of torque, internal power factor, optimum split and magnetic ratio as function of the speed depend on the selected lamination material. However, mainly the rate of decrement of the optimal performance is affected by the materials. Therefore, several general conclusions regarding the worsening of the maximum torque design solution as the speed increases can be drawn.

- The iron ribs affect more the q-axis inductance and so the power factor rather than the torque.

- The iron losses increment heavily influences the maximum current and so the torque capability for a certain level of the total losses, and slightly improves the power factor.

For the considered lamination material (a cobalt-iron alloy with good magnetic performance and standard structural characteristic), the optimal split ratio tends to remain almost constant as the speed increases while the optimal magnetic ratio tends to decrease. Clearly this behaviour is highly dependent on the lamination material and so the balance between the iron losses and iron ribs effects. Experimental measurements on an existing prototype validate the proposed design approach which is introducing a set of general guidelines addressing the design of high speed SyR machines.

\section{REFERENCES}

[1] A. T. de Almeida, F. J. T. E. Ferreira, and G. Baoming. Beyond induction motors-technology trends to move up efficiency. IEEE Transactions on Industry Applications, 50(3):2103-2114, May 2014.

[2] K. Lang, A. Muetze, R. Bauer, and S. Pircher. Comparison of induction and synchronous reluctance machine based actuators for elevated temperature environments. IEEE Transactions on Energy Conversion, 31(3):1012-1022, 2016.

[3] R. Moghaddam, F. Magnussen, and C. Sadarangani. Novel rotor design optimization of synchronous reluctance machine for low torque ripple. In 2012 XXth International Conference on Electrical Machines, pages 720-724, 2012.

[4] M. Sanada, K. Hiramoto, S. Morimoto, and Y. Takeda. Torque ripple improvement for synchronous reluctance motor using an asymmetric flux barrier arrangement. IEEE Transactions on Industry Applications, 40(4):1076-1082, 2004.

[5] J. H. Lee. Optimum design criteria for maximum torque density and minimum torque ripple of synrm according to the rated wattage using response surface methodology. IEEE Transactions on Magnetics, 45(3):1578-1581, 2009.

[6] E. Howard, M. J. Kamper, and S. Gerber. Asymmetric flux barrier and skew design optimization of reluctance synchronous machines. IEEE Transactions on Industry Applications, 51(5):3751-3760, 2015.

[7] D.A. Staton, T.J.E. Miller, and S.E. Wood. Maximising the saliency ratio of the synchronous reluctance motor. Electric Power Applications, IEE Proceedings B, 140(4):249-259, July 1993.

[8] N. Bianchi. Synchronous reluctance and interior permanent magnet motors. In Electrical Machines Design Control and Diagnosis (WEMDCD), 2013 IEEE Workshop on, pages 75-84, 2013.

[9] M. Ferrari, N. Bianchi, A. Doria, and E. Fornasiero. Design of synchronous reluctance motor for hybrid electric vehicles. IEEE Transactions on Industry Applications, 51(4):3030-3040, 2015.

[10] M. Ferrari, N. Bianchi, and E. Fornasiero. Analysis of rotor saturation in synchronous reluctance and pm-assisted reluctance motors. Industry Applications, IEEE Transactions on, 51(1):169-177, 2015.

[11] A. Tessarolo. Modeling and analysis of synchronous reluctance machines with circular flux barriers through conformal mapping. Magnetics, IEEE Transactions on, 51(4):1-11, April 2015.

[12] M. Murataliyev, M. Degano, and M. Galea. A novel sizing approach for synchronous reluctance machines. IEEE Transactions on Industrial Electronics, 68(3):2083-2095, 2021.

[13] A. Vagati, M. Pastorelli, F. Scapino, and G. Franceschini. Impact of cross saturation in synchronous reluctance motors of the transverse-laminated type. Industry Applications, IEEE Trans on, 36(4):1039-1046, 2000. 
[14] A. Vagati, M. Pastorelli, and G. Franceschini. High-performance control of synchronous reluctance motors. Industry Applications, IEEE Transactions on, 33(4):983-991, 1997.

[15] G. Bacco, N. Bianchi, and H. Mahmoud. A nonlinear analytical model for the rapid prediction of the torque of synchronous reluctance machines. IEEE Transactions on Energy Conversion, 33(3):1539-1546, 2018.

[16] H. Mahmoud and N. Bianchi. Non-linear analytical model of eccentric synchronous reluctance machines considering the iron saturation and slotting effect. IEEE Transactions on Industry Applications, 53(3):20072015, 2017.

[17] A. Vagati. The synchronous reluctance solution: a new alternative in ac drives. In Industrial Electronics, Control and Instrumentation, 1994. IECON '94., 20th Int. Conference on, volume 1, pages 1-13 vol.1, 1994.

[18] A. Vagati, G. Franceschini, I. Marongiu, and G. P. Troglia. Design criteria of high performance synchronous reluctance motors. In Industry Applications Society Annual Meeting, 1992., Conference Record of the 1992 IEEE, pages 66-73 vol.1, 1992.

[19] S. Ferrari and G. Pellegrino. Feafix: Fea refinement of design equations for synchronous reluctance machines. IEEE Transactions on Industry Applications, 56(1):256-266, 2020.

[20] M. Di Nardo, M. Galea, C. Gerada, M. Palmieri, F. Cupertino, and S. Mebarki. Comparison of multi-physics optimization methods for high speed synchronous reluctance machines. In Industrial Electronics Society, IECON 2015 - 41st Annual Conference of the IEEE, pages 002771-002776, Nov 2015.

[21] M. Di Nardo, M. Galea, C. Gerada, M. Palmieri, and F. Cupertino. Multiphysics optimization strategies for high speed synchronous reluctance machines. In Energy Conversion Congress and Exposition (ECCE), 2015 IEEE, pages 2813-2820, 2015.

[22] M. Palmieri, M. Perta, and F. Cupertino. Design of a 50.000-r/min synchronous reluctance machine for an aeronautic diesel engine compressor. IEEE Transactions on Industry Applications, 52(5):3831-3838, Sept 2016.

[23] M. D. Nardo, G. L. Calzo, M. Galea, and C. Gerada. Design optimization of a high-speed synchronous reluctance machine. IEEE Transactions on Industry Applications, 54(1):233-243, 2018.

[24] A. Credo, G. Fabri, M. Villani, and M. Popescu. Adopting the topology optimization in the design of high-speed synchronous reluctance motors for electric vehicles. IEEE Transactions on Industry Applications, 56(5):5429-5438, 2020.

[25] C. Babetto, G. Bacco, and N. Bianchi. Analytical power limits curves of high-speed synchronous reluctance machines. IEEE Transactions on Industry Applications, 55(2):1342-1350, 2019.

[26] Mauro Di Nardo. Design of High Speed Synchronous Reluctance Machine. PhD thesis, University of Nottingham, UK, 2017.

[27] F. Cupertino et al. "Synchronous Reluctance (machines) evolution". Accessed: Dec. 18, 2020. [Online]. Available: https://sourceforge.net/projects/syr-e/.

[28] A. Vagati, B. Boazzo, P. Guglielmi, and G. Pellegrino. Design of ferriteassisted synchronous reluctance machines robust toward demagnetization. IEEE Transactions on Industry Applications, 50(3):1768-1779, 2014.

[29] C. Babetto, G. Bacco, and N. Bianchi. Synchronous reluctance machine optimization for high-speed applications. IEEE Transactions on Energy Conversion, 33(3): 1266-1273, 2018.

[30] W. Q. Chu and Z. Q. Zhu. Average torque separation in permanent magnet synchronous machines using frozen permeability. IEEE Transactions on Magnetics, 49(3):1202-1210, 2013.

[31] J. A. Walker, D. G. Dorrell, and C. Cossar. Flux-linkage calculation in permanent-magnet motors using the frozen permeabilities method. IEEE Transactions on Magnetics, 41(10):3946-3948, 2005.

[32] M. Di Nardo, G. L. Calzo, M. Galea, and C. Gerada. Structural design optimization of a high speed synchronous reluctance machine. In 2016 XXII International Conference on Electrical Machines (ICEM), pages 2073-2079, Sept 2016.

[33] "Motor-CAD". Accessed: Jan. 11, 2021. [Online]. Available: https://www.motor-design.com.

[34] E. Armando, R. I. Bojoi, P. Guglielmi, G. Pellegrino, and M. Pastorelli. Experimental identification of the magnetic model of synchronous machines. Industry Applications, IEEE Transactions on, 49(5):2116$2125,2013$.

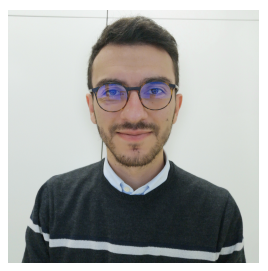

Gianvito Gallicchio received the B.Sc. (Hons.) and M.Sc. (Hons.) degrees in electrical engineering from the Politecnico di Bari, Bari, Italy, in 2016 and 2018 , respectively. He is currently working toward the Ph.D. degree with the Electrical Machines and Drives Group, Politecnico di Bari, Bari, Italy.

His main research interests include the analysis, modelling and design of magnetic couplers for industrial applications and the design of electrical machines, including permanent magnet and synchronous reluctance machines, for aerospace sector.

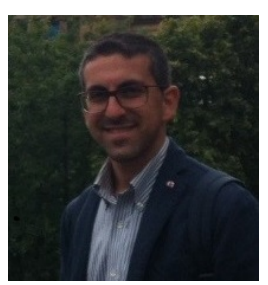

Mauro Di Nardo (Member, IEEE) received the M.Sc. (Hons.) degree in electrical engineering from the Polytechnic University of Bari, Italy, in 2012 and the Ph.D. degree in electrical machine design from the University of Nottingham, U.K., in 2017. From 2017 to 2019, he was Head with the AROL R\&D Team within the Polytechnic University of Bari leading industrial projects on electrical drives design for mechatronics applications. Since the 2019, he is with the Power Electronics and Machine Control Group of the University of Nottingham as Research Fellow working on wide variety of projects of high industrial and scientific impacts. His research interests include the analysis, modelling, and design optimizations of permanent magnet and synchronous reluctance machines for automotive, aerospace and household sectors, induction motor for industrial applications as well as niche machine topologies such as bearingless and hysteresis motor.

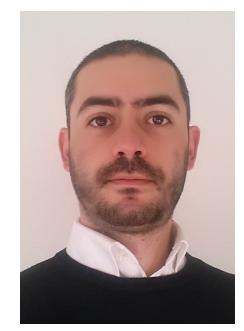

Marco Palmieri received the M.Sc. and Ph.D. degrees in electrical engineering from Politecnico di Bari, Bari, Italy, in 2011 and 2016, respectively. Since 2017 he has been with the Department of Electrical and Information Engineering, Politecnico di Bari, where he is currently a post-doc researcher. From 2011 to 2015, he was with the Energy Factory Bari Research Team, working on high-speed electrical machines for aeronautical applications. In 2014 he joined the Power Electronics, Control, and Machines Research Group of the University of Nottingham, working on electrical machines for aeronautical applications. In 2019 he was visiting researcher with the Laboratory of Actuation Technology of the Saarland University. His research interests include the design of high-speed electrical machines by means of optimization algorithms and finite element analysis.

Dr. Palmieri co-received the Prize Paper Award from the IEEE Industrial Electronics Society Electrical Machines Committee in 2015.

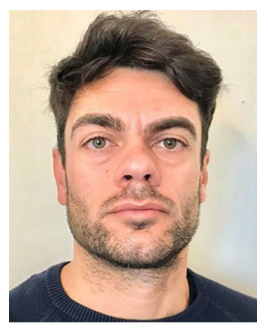

Alessandro Marfoli received the M.Sc. in Electrical Engineering from the University of Pisa, Italy, in 2015 and the Ph.D. degree in electrical machine design from the University of Nottingham (UK) in 2020. He is currently a Research Fellow within the same institution working on wide variety of projects of high industrial and scientific impacts. His main research interests involves the modelling, analysis and optimization of electrical machines including induction and synchronous machines also for bearingless applications. 


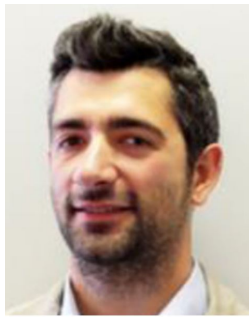

Michele Degano SM'12) received his Master's degree in Electrical Engineering from the University of Trieste, Italy, in 2011, and his Ph.D. degree in Industrial Engineering from the University of Padova, Italy, in 2015. Between 2014 and 2016, he was a postdoctoral researcher at The University of Nottingham, UK, where he joined the Power Electronics, Machines and Control (PEMC) Research Group. In 2016 he was appointed Assistant Professor in Advanced Electrical Machines, at The University of Nottingham, UK. He was promoted Associate Professor in 2020. His main research focuses on electrical machines and drives for industrial, automotive, railway and aerospace applications, ranging from small to large power. He is currently the PEMC Director of Industrial Liaison leading research projects for the development of hybrid electric aerospace platforms and electric transports.

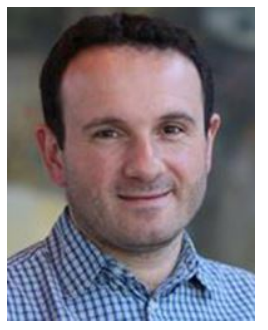

Chris Gerada SM'12) is an Associate Pro-ViceChancellor for Industrial Strategy and Impact and Professor of Electrical Machines. His principal research interest lies in electromagnetic energy conversion in electrical machines and drives, focusing mainly on transport electrification. $\mathrm{He}$ has secured over $£ 20 \mathrm{M}$ of funding through major industrial, European and UK grants and authored more than 350 referred publications. He received the $\mathrm{Ph} . \mathrm{D}$. degree in numerical modelling of electrical machines from The University of Nottingham, Nottingham, U.K., in 2005. He subsequently worked as a Researcher with The University of Nottingham on high-performance electrical drives and on the design and modelling of electromagnetic actuators for aerospace applications. In 2008, he was appointed as a Lecturer in electrical machines; in 2011, as an Associate Professor; and in 2013, as a Professor at The University of Nottingham. He was awarded a Research Chair from the Royal Academy of Engineering in 2013. Prof. Gerada served as an Associate Editor for the IEEE TRANSACTIONS ON INDUSTRY APPLICATIONS and is the past Chair of the IEEE IES Electrical Machines Committee.

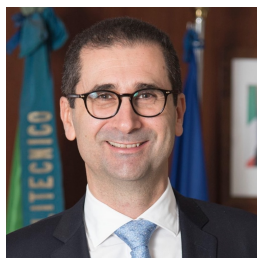

Francesco Cupertino (M'08-SM'12) received the Laurea and Ph.D. degrees in electrical engineering from the Politecnico di Bari, Bari, Italy, in 1997 and 2001, respectively. Since 2001, he has been with the Department of Electrical and Information Engineering, Politecnico di Bari, Bari, Italy, where he is currently a Full Professor of converters, electrical machines, and drives.

$\mathrm{He}$ is the Scientific Director of four public/private laboratories at Politecnico di Bari that enroll more than 50 researchers; the laboratory Energy Factory

Bari, with GE AVIO, aimed at developing research projects in the fields of aerospace and energy; the More Electric Transportation laboratory, with CVIT SpA (BOSCH Group), aimed at developing technologies for sustainable mobility; Cyber Physical Systems AROL Bari, with AROL SpA, focused on closure systems for food and beverage; Innovation for Mills, with Casillo Group and Idea75, focused in the Industry4.0 applications for wheat processing. He has authored or coauthored more than 130 scientific papers on these topics. His research interests include the design of synchronous electrical machines, motion control of high performances electrical machines, applications of computational intelligence to control, and sensorless control of ac electric drives.

Dr. Cupertino was the recipient of two Best Paper Awards from the Electrical Machines Committee of the IEEE Industry Application Society and from the homonymous Committee of the IEEE Industrial Electronics Society, in 2015. F. Cupertino is currently the rector of Politecnico di Bari. 